\title{
ANALISA KELAYAKAN INVESTASI ANGKUTAN UMUM (ANGKOT) KOTA PARIAMAN
}

\author{
Nadra Arsyad ${ }^{1}$,Purnawan ${ }^{2}$,dan Titi Kurniati ${ }^{3}$
}

\begin{abstract}
ABSTRAK
Angkutan umum merupakan fasilitas umum yang bisa membawa penumpang dari asal ke tujuan perjalanan mereka atau sarana untuk mempermudah aksessibilitas. Penelitian ini bertujuan untuk melakukan analisa kelayakan investasi dari angkutan umum (angkot) Kota Pariaman, dengan berbagai skenario investasi. Metoda perhitungan yang digunakan yaitu BCR, NPV, IRR, pay back period, dan break even point, metoda ini digunakan untuk menilai kelayakan suatu investasi angkot. Jumlah angkutan umum kota Pariaman terdiri dari 46 unit, yang terdiri dari dua trayek yaitu trayek Pasar Pariaman-Naras dan trayek Pasar Pariaman-Lapai. Trayek Pasar Pariaman-Naras pendapatan rata-rata perhari sebesar Rp.257.000,- sedangkan pengeluaran ratarata pertahun sebesar Rp. 238.512,-. Untuk trayek Pasar Pariaman-Lapai pendapatan rata-rata perhari sebesar Rp.270.769,-, sedangkan pengeluaran rata-rata sebesar Rp. 246.491,-. Berdasarkan hasil perhitungan dengan tingkat bunga $11 \%$, untuk umur ekonomis 12 tahun dan 11 tahun dan variasi pendapatan maksimum dengan pengeluaran minimum, angkot dinyatakan layak investasi. Pada perencanaan investasi dengan menggunakan tingkat bunga 11\%, maka untuk umur ekonomis 10 dan 15 tahun bisa dinyatakan layak investasi.
\end{abstract}

Kata kunci : Investasi,angkutan umum, pendapatan, pengeluaran, kelayakan

\section{PENDAhUluan}

Angkutan umum merupakan fasilitas umum yang bisa membawa penumpang dari asal ke tujuan perjalanan mereka atau sarana untuk mempermudah aksessibilitas. Oleh sebab itu angkutan umum tidak bisa terlepas dari kehidupan sehari-hari masyarakat, maka sebagai sarana fasilitas umum, angkutan umum harus bisa memberikan pelayanan kepada penumpang agar tidak beralih terhadap kendaraan pribadi. Disamping angkutan umum dapat memberikan pelayanan, angkutan umum juga dapat membuka lapangan kerja bagi mereka yang tidak memiliki pendidikan tinggi.

Sebagaimana dapat kita lihat dalam kehidupan masyarakat bahwa angkutan umum di Indonesia khususnya Kota Pariaman hanya diminati bagi kalangan menengah ke bawah. Hal ini disebabkan karena menggunakan kendaraan pribadi lebih cepat sampai ditujuan dan lebih nyaman. Dimana mereka bebas bepergian sesuai dengan keinginan mereka tanpa harus menunggu seperti yang dialami penumpang angkutan umum. Permasalahan seperti ini yang membuat orang malas menggunakan angkutan umum.

Hal ini yang melatar belakangi penelitian ini karena melihat kondisi dilapangan dimana angkutan umum kesulitan mencari penumpang sehingga jumlah angkutan umum tersebut yang beroperasi

\footnotetext{
${ }^{1}$ Mahasiswa Pascasarjana Jurusan Teknik Sipil Fakultas Teknik Universitas Andalas nadrinal907@gmail.com

${ }^{2}$ Staf Pengajar Jurusan Teknik Sipil Fakultas Teknik Universitas Andalas Purnawan@ft.unand.ac.id

${ }^{3}$ Staff Pengajar Jurusan Teknik Sipil Fakultas Teknik Universitas AndalasTiti Kurniati@ft unand ac.id
} 
berkurang atau kebanyakan waktu berhenti disuatu tempat dari pada beroperasi. Keadaan yang demikian akan berdampak pada pendapatan dari angkutan tersebut. Oleh karena angkutan umum merupakan lapangan kerja, maka diharapkan keberadaan angkutan umum bisa menjadi sumber penghasilan yang layak. Karena adanya angkutan umum juga dapat dijadikan sebagai investasi bagi pemiliknya melalui pemasukan yang didapat dari operasional angkutan umum tersebut sehari-hari.

\section{TINJAUAN PUSTAKA DAN LANDASAN TEORI}

\subsection{Evaluasi Kelayakan Ekonomi}

\subsubsection{Depresiasi, Book Value, dan Kemajuan Penting}

Menurut Ardalan (2000), depresiasi adalah penyusutan nilai dari fasilitas karena kadar atau lamanya pemakaian. Depresiasi garis lurus, pada metoda ini dimana harga adalah pembentang lebih seragam terdiri dari jumlah tahun $\mathrm{N}$ disebut kegiatan pada depresiasi harga, ini bertujuan adalah initial cost $\mathrm{P}$ minus memperkirakan nilai sisa $\mathrm{S}$ pada akhir dari sebuah proyek.

$$
\text { Depresiasi / tahun }=\frac{\mathrm{P}-\mathrm{S}}{\mathrm{N}}
$$

Metode depresiasi:

1. Metode garis lurus (straight line method)

2. Metode keseimbangan menurun (declining balance method/ double declining balance method)

3. Metode jumlah angka tahun (sum of the year digits method)

4. Metode unit produksi (unit of production method)

\subsection{Metode Nilai Sekarang Bersih (Net Present Value)}

Metoda nilai sekarang (the present worth method) atau net present value. Net present value adalah present value aliran kas masuk dikurangi dengan present value aliran kas keluar. Dasar dari metode nilai sekarang ini bahwa semua penerimaan atau pembayaran di masa yang akan datang yang berhubungan dengan suatu proyek investasi akan dirubah ke nilai sekarang, dengan menggunakan suatu tingkat suku bunga, yang seperti sebelumnya. NPV (net present value) adalah selisih antara present value dari investasi dengan nilai sekarang dari penerimaan-penerimaan kas bersih di masa yang akan datang. Untuk menghitung nilai sekarang perlu ditentukan tingkat bunga yang relevan. Metode NPV adalah sangat jelas, untuk menutupi kelemahan pada metode-metode lain. NPV sebesar nol menyiratkan bahwa arus kas proyek sudah mencukupi untuk membayar kembali modal yang diinvestasikan dan memberikan tingkat pengembalian yang diperlukan atas modal tersebut. Jika proyek NPV positif, maka proyek tersebut menghasilkan lebih banyak kas dari yang dibutuhkan untuk menutup utang dan memberikan pengembalian yang diperlukan kepada pemegang saham perusahaan. Oleh karena itu jika perusahaan mengambil proyek yang memiliki NPV positif maka posisi pemegang saham meningkat.

Menurut Tamin (2008), persamaan umum untuk metoda ini adalah sebagai berikut:

$$
\mathrm{NPV}=(\mathrm{Bo}-\mathrm{Co})+\frac{\left(\mathrm{B}_{1}-\mathrm{C}_{2}\right)}{(1+\mathrm{r})^{2}}+\frac{\left(\mathrm{B}_{2}-\mathrm{C}_{2}\right)}{(1+\mathrm{r})^{2}}+\ldots+\frac{\left(\mathrm{B}_{\mathrm{N}}-\mathrm{C}_{\mathrm{N}}\right)}{(1+\mathrm{r})^{2}}
$$

atau

$$
\mathrm{NPV}=\sum_{i=1}^{n}\left[\frac{(\mathrm{Bt}-\mathrm{Ct}}{(1+\mathrm{r})^{\mathrm{t}}}\right]
$$


dimana:
NPV : Nilai sekarang bersih
$\mathrm{B}_{\mathrm{i}} \quad: \quad$ Keuntungan pada tahun $\mathrm{i}$
$\mathrm{Ci} \quad$ : Biaya pada tahun $\underline{\mathrm{i}}$
$\mathrm{R} \quad$ : Tingkat suku bunga (discount rate) yang menggambarkan pertambahan nilai uang bila uang yang ada tidak digunakan untuk proyek tingkat suku bunga ini sudah termasuk inflasi.
$\mathrm{N} \quad$ : Umur ekonomi proyek, dimulai dari tahap perencanaan sampai akhir umur rencana jalan.

Net present value adalah selisih antara present value benefit dikurangi dengan present value cost. Hasil NPV dari suatu proyek akan dikatakan layak secara finasial adalah yang menghasilkan nilai NPV bernilai positif. dalam hal ini semua rencana akan dilaksanakan apabila NPV $>0$, atau persamaan di atas memenuhi:

$$
\text { Net Present Value }(\mathrm{NPV})=\mathrm{PV}_{\text {benefit }}-\mathrm{PV}_{\text {cost }}=\text { Positif }
$$

Hal tersebut berarti bahwa pembangunan konstruksi jalan akan memberikan keuntungan, di mana benefit cash flow positif akan lebih besar daripada cost cashflow negatif.

Menurut Ardalan (2000), untuk mengimplementasikan metode ini, kita mengikuti proses sebagai berikut:

1. nilai sekarang dari setiap arus kas, termasuk arus masuk dan arus keluar yang didiskontokan pada biaya modal proyek.

2. Jumlahkan arus kas yang didiskontokan ini, hasil ini didefinisikan sebagai NPV proyek.

3. Jika NPV adalah positif, maka proyek harus diterima, sementara jika NPV adalah negatif, maka proyek harus ditolak. Jika dua proyek dengan NPV positif adalah mutually exclusive, maka salah satu nilai NPV terbesar harus dipilih.

\subsection{Metode Tingkat Pengembalian Internal (Internal Rate of Return)}

Metoda tingkat pengembalian (rate of return method) atau adalah metode perbandingan alternatifalternatif investasi yang paling dikenal. Metode ini dikenal sebagai internal-rate-of-return (IRR). IRR adalah tingkat diskonto (discount rate) yang menyamakan present value aliran kas masuk dengan present value aliran kas keluar. IRR (internal Rate of Return), metode IRR ini digunakan untuk mencari tingkat bunga yang menyamakan nilai sekarang dari arus kas yang diharapkan di masa datang, atau penerimaan kas, dengan mengeluarkan investasi awal. Caranya, dengan menghitung nilai sekarang dari arus kas suatu investasi dengan menggunakan suku bunga yang wajar, misalnya $10 \%$. Kemudian di bandingkan dengan biaya investasi, jika nilai investasi lebih kecil, maka di coba lagi dengan penghitungan suku bunga yang lebih tinggi demikian seterusnya sampai biaya investasi menjadi sama besar. Apabila dengan suku bunga wajar tadi nilai investasi lebih besar, maka harus di coba lagi dengan suku bunga yang lebih rendah sampai mendapatkan nilai investasi yang sama besar dengan nilai sekarang.

Menurut Ibrahim (1997), Persamaan umum untuk metoda ini adalah sebagai berikut:

$$
\operatorname{IRR}=\mathrm{i}_{1}+\frac{\mathrm{NPV} 1}{(\mathrm{NPV} 1-\mathrm{NPV} 2} \cdot\left(\mathrm{i}_{2}-\mathrm{i}_{1}\right)
$$

Dimana : $\mathrm{I}_{1}=$ tingkat discount rate yang menghasilkan $\mathrm{NPV}_{1}$

$$
\mathrm{I}_{2}=\text { tingkat discount rate yang menghasilkan } \mathrm{NPV}_{2}
$$


Kegunaan dari metoda RR adalah :

1. RR untuk suatu tujuan tunggal ditentukan dengan mempersamakan penerimaan-penerimaan nilai sekarang (PW) atau nilai tahunan (AW) kepada pengeluaran-pengeluaran nilai sekarang (PW) atau nilai tahunan (AW). Yang kemudian suatu tingkat bunga dicari untuk membuat discounted cashflow sehingga akan memenuhi kesamaan:

2. Dengan cara : cari nilai i, sehingga PW (penerima) $=\mathrm{PW}$ (pengeluaran) Untuk itu hubungan yang jelas apabila discounted cash flows saling mengurangi satu sama lain untuk menjadi sama dengan nol, maka dicari nilai i, sehingga PW (penerimaan) $-\mathrm{PW}$ (pengeluaran) $=0$

\subsection{Metode Nisbah Keuntungan Biaya (Benefit Cost Ratio)}

Benefit cost ratio (B/C-R) yang merupakan perbandingan antara present value benefit dibagi dengan present value cost. Hasilnya B/C-R dari suatu proyek dikatakan layak secara ekonomi, bila nilai B/C$\mathrm{R}$ adalah lebih besar dari 1 (satu). Sebaliknya apabila nilai B/C-R yang lebih kecil dari 1 (satu) menunjukan investasi ekonomi yang tidak menguntungkan. Kelayakan investasi pada angkutan umum terutama didasarkan pada analisis manfaat dan biaya (benefit-cost), nilai sekarang (net present value), dan laju pengembalian modal (internal rate of return).

Persamaan untuk metoda ini adalah sebagai berikut:

$$
\begin{aligned}
& \mathrm{B} / \mathrm{C} \text { Nett }=\text { Present value nett benefit/Capita cost } \\
& \mathrm{BCR}=\text { nilai sekarang total manfaat/nilai sekarang total biaya }
\end{aligned}
$$

\section{METODOLOGI}

Bagan alir penelitian akan diperlihatkan pada Gambar 3.1 dibawah ini.

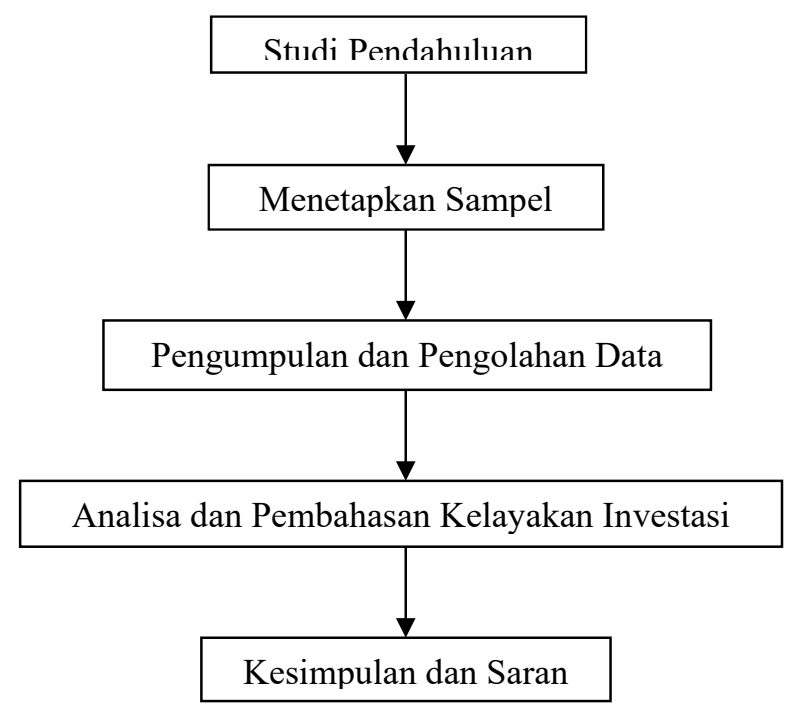

Gambar 3.1 Bagan Alir Penelitian 
a. Studi Pendahuluan

Lokasi survey di Kota Pariaman, yang terdiri dari dua trayek diantaranya Pasar PariamanNaras dan Pasar Pariaman-Lapai. Jumlah surveyor yang difungsikan sebanyak 4 orang.

b. Menetapkan Sampel

Pada penelitian ini penetapan jumlah sampel digunakan metoda revealed preference, menurut Pearmain dan Swanson (1990), bahwa data dianggap mencukupi apabila pengambilan sampel minimal 30 sampel dari populasi. Oleh karena itu, untuk memperoleh data yang akurat maka terlebih dahulu kita tetapkan jumlah sampel pada penelitian ini sebanyak 46 unit angkutan umum kota. Untuk trayek pasar Pariaman-Lapai yaitu sebanyak 26 buah angkutan kota, sedangkan untuk trayek Pasar Pariaman-Naras yaitu 20 buah angkutan kota. Jumlah angkot keluaran 2001 sebanyak 18, dan 2002 sebanyak 20.

c. Pengumpulan data

Pengumpulan data terdiri dari data sekunder dan data primer. Data sekunder diperoleh langsung dari sumbernya yaitu pemerintah kota yaitu jumlah angkutan kota yang beroperasi, jumlah trayek, biaya retribusi dan STNK atau pajak kendaraan sedangkan data primer diperoleh langsung dari sumbernya dengan melakukan survey dan pengamatan dilapangan, pada penelitian ini data primer bersumber dari pemilik dan sopir angkutan kota, survey pengambilan data, untuk mendapatkan komponen berikut dari seluruh angkutan umum yang beroperasi :

I. Cost :

1. Pemakaian bensin (BBM)

2. Pemakaian suku cadang

3. Gaji sopir

4. Ban

5. Servis

6. Penambahan oli mesin

7. Retribusi

8. Asuransi kendaraan

9. STNK/ Pajak kendaraan

10. KIR

11. Biaya pengelolaan

12. Asuransi

13. Setoran

II. Benefit :

1. Pendapatan / operasi angkutan umum

\section{ANALISA DAN PEMBAHASAN}

\subsection{Analisa Pengembalian Modal}

Break even point (titik impas) merupakan teknik untuk memperkirakan waktu pengembalian modal. Pay back period digunakan untuk mengetahui berapa lama jangka waktu pengembalian modal atau untuk mengukur kecepatan pengembalian dana investasi melalui pendapatan-pendapatan yang dihasilkan angkutan umum selama masa operasi.

\subsubsection{Angkutan kota untuk keluaran tahun 2001}

Angkutan umum kota untuk tahun keluaran 2001, merupakan angkutan umum yang pertama keluar. Jika dihitung umur ekonomisnya sama dengan 12 tahun artinya angkutan umum kota ini telah digunakan selama 12 tahun. Berdasarkan hasil survey pembelian angkutan umum di Kota Pariaman yaitu dengan sistem kredit, dengan uang muka sebesar Rp. 25.000.000,- dan jumlah cicilan dalam setahun yaitu Rp. 21.000.000,-. Dari hasil survey diperkirakan kenaikan pengeluaran setiap tahun 
yaitu sebesar 5\% dan kenaikan pendapatan setiap tahun yaitu sebesar 1\% dengan mengasumsikan tingkat suku bunga tetap setiap tahun sebesar $11 \%$.

Diketahui :

$$
\begin{aligned}
& \mathrm{P}(\text { pengeluaran awal }) \quad=\text { Rp. 80.000.000,- } \\
& \mathrm{S} \text { ( nilai sisa ) } \quad=\text { Rp. 50.000.000,- } \\
& \mathrm{N} \text { (umur ekonomis) } \quad=12 \text { Tahun } \\
& \text { Depresiasi }=\frac{\mathrm{P}-\mathrm{S}}{\mathrm{N}} \\
& \text { Depresiasi }=\text { Rp. } 2 \cdot 500.000,00 \quad \mathrm{Jt} / \mathrm{tahun}
\end{aligned}
$$

Hasil perhitungan dengan metode BCR, IRR dan NPV bisa dilihat pada Tabel 4.1 di bawah ini.

Tabel 4.1. Hasil perhitungan untuk umur ekonomis 12 tahun

\begin{tabular}{|l|l|l|}
\hline No & Metode & Nilai \\
\hline 1 & BCR & 1,02 \\
\hline 2 & IRR & $15 \%$ \\
\hline 3 & NVP & Rp. $11.140 .923,-$ \\
\hline
\end{tabular}

Berdasarkan Tabel 4.1 diatas bahwa didapatkan nilai $\mathrm{BCR}=1,02$ dan nilai NPV= Rp. 11.140.923,maka angkutan umum untuk umur ekonomis 12 tahun dinyatakan layak. Dari hasil perhitungan dengan metode IRR didapatkan tingkat suku yaitu 15\%. Kemudian nilai break even point dan pay back period, akan ditampilkan pada Gambar 4.1

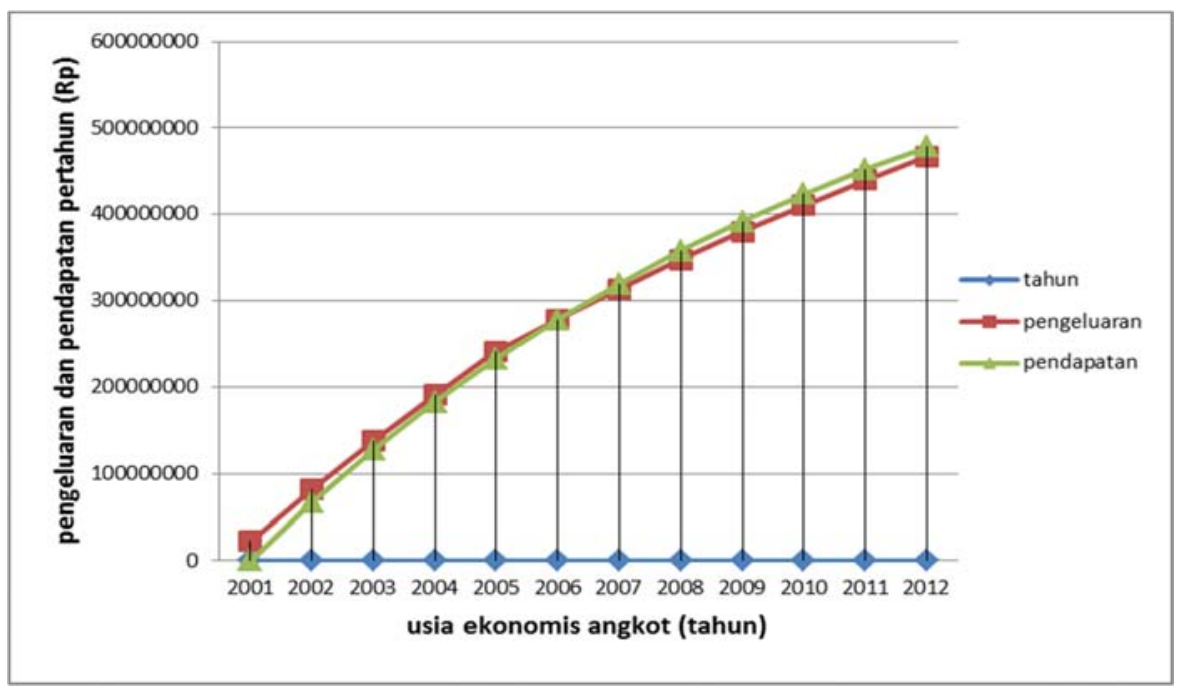

Gambar 4.1. Break even point dan pay back period angkot keluaran 2001

Berdasarkan Gambar 4.1, break even point terjadi pada tahun ke 7, tepatnya tahun 2007 nilai penghasilan dan pendapatan sama dan terlihat persilangan pada kurva tersebut dimana modal sudah kembali. Berdasarkan hasil survey bahwa angkutan umum kota keluaran 2001 diperkirakan harga jual yaitu Rp. 50.000.000,- dan pemilik tidak bisa membeli angkutan umum yang baru, karena keuntungan yang diperoleh ditambah nilai sisa tidak mencukupi membeli angkot baru. 


\subsubsection{Angkutan kota untuk keluaran tahun 2002}

Angkutan umum kota untuk tahun keluaran 2002, merupakan angkutan umum yang pertama keluar. Jika dihitung umur ekonomisnya sama dengan 11 tahun artinya angkutan umum kota ini telah digunakan selama 11 tahun. Berdasarkan hasil survey pembelian angkutan umum di Kota Pariaman yaitu dengan sistem kredit, dengan uang muka sebesar Rp. 30.000.000,- dan jumlah cicilan dalam setahun yaitu Rp. 21.000.000,-. Dari hasil survey diperkirakan kenaikan pengeluaran setiap tahun yaitu sebesar 5\% dan kenaikan pendapatan setiap tahun yaitu sebesar $1 \%$ dengan mengasumsikan tingkat suku bunga tetap setiap tahun sebesar 11\%, kenaikan untuk angkot keluaran tahun 2002 diperkirakan sama dengan angkot keluaran 2001.

Diketahui :

$\mathrm{P}($ pengeluaran awal $)=$ Rp. 80.000.000,-

$\mathrm{S}$ ( nilai sisa $) \quad=$ Rp. $50.000 .000,-$

$\mathrm{N}$ ( umur ekonomis ) = 11 Tahun

$$
\begin{aligned}
\text { Depresiasi } & =\frac{\mathrm{P}-\mathrm{S}}{\mathrm{N}} \\
\text { Depresiasi } & =\text { Rp. 2.727.272,- Jt/tahun }
\end{aligned}
$$

Hasil perhitungan dengan metode BCR, IRR dan NPV bisa dilihat pada Tabel 4.2 di bawah ini.

Tabel 4.2. Hasil perhitungan untuk umur ekonomis 11 tahun

\begin{tabular}{|l|l|l|}
\hline No & Metode & Nilai \\
\hline 1 & BCR & 1,12 \\
\hline 2 & IRR & $20 \%$ \\
\hline 3 & NVP & Rp. 53.889.108,-- \\
\hline
\end{tabular}

Berdasarkan Tabel 4.2 diatas bahwa didapatkan nilai BCR=1,12 dan nilai NPV = Rp. 53.889.108,maka angkutan umum untuk umur ekonomis 11 tahun dinyatakan layak. Dari hasil perhitungan dengan metode IRR didapatkan tingkat suku yaitu $20 \%$. Kemudian nilai break even point dan pay back period, akan ditampilkan pada Gambar 4.2

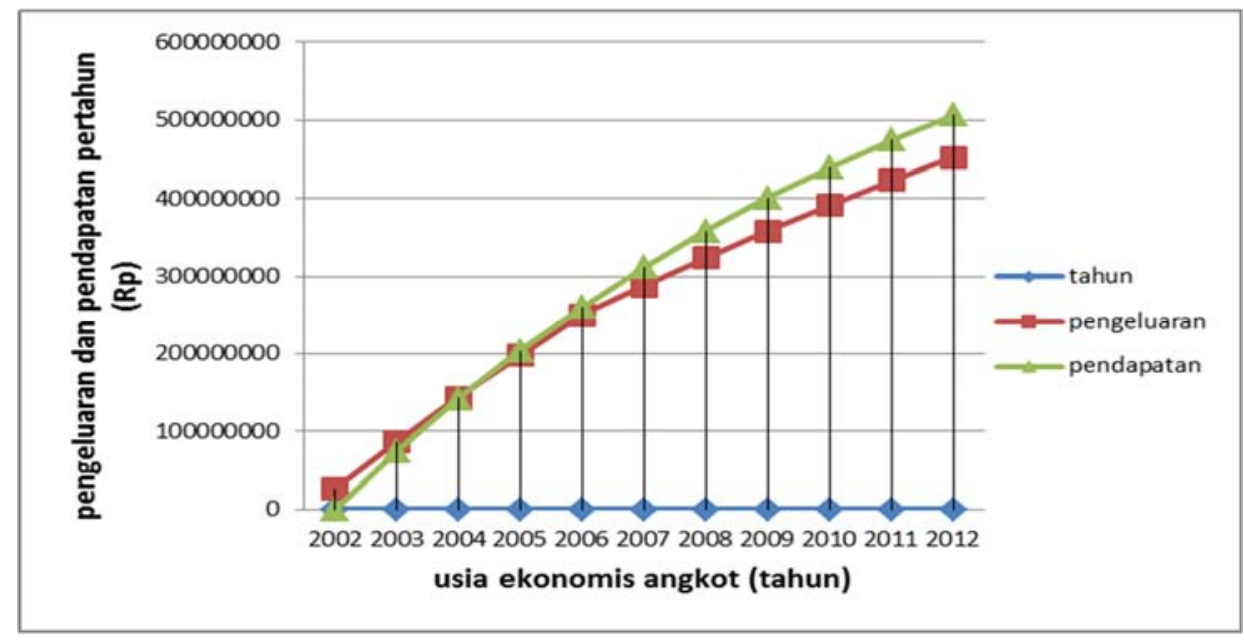

Gambar 4.2. Break even point dan pay back period angkot keluaran 2002 
Berdasarkan Gambar 4.2 dapat dinyatakan bahwa tahun 2005 modal sudah kembali dan pay back periodnya selama 5 tahun. Dari hasil perhitungan dari break even point dan pay back period bahwa angkot dinyatakan layak investasi.

\subsubsection{Angkutan kota untuk umur ekonomis 10 tahun}

Angkutan umum kota diasumsikan keluaran tahun keluaran 2012, dengan sistem pembelian sistim kredit. Direncanakan umur ekonomis selama 10 tahun, nilai pendapatan dan pengeluaran yang digunakan, merupakan pendapatan dan pengeluran rata-rata angkutan umum kota.

Diketahui :

$$
\begin{aligned}
& \mathrm{P}(\text { pengeluaran awal })=\text { Rp. } 120.000 .000,00 \\
& \mathrm{~S}(\text { nilai sisa })=\text { Rp. } 55 \cdot 000.000,00 \\
& \mathrm{~N} \text { ( umur ekonomis }) \quad=10 \text { Tahun } \\
& \text { Depresiasi }=\frac{\mathrm{P}-\mathrm{S}}{\mathrm{N}} \\
& \text { Depresiasi }=\text { Rp. 13.000.000,- Jt/tahun }
\end{aligned}
$$

Hasil perhitungan dengan metode BCR, IRR dan NPV, dengan tingkat bunga $11 \%$ bisa dilihat pada Tabel 4.3 di bawah ini.

Tabel 4.3. Hasil perhitungan untuk umur ekonomis 10 tahun

\begin{tabular}{|l|l|l|}
\hline No & Metode & Nilai \\
\hline 1 & BCR & 1,02 \\
\hline 2 & IRR & $17 \%$ \\
\hline 3 & NVP & Rp. $10.139 .439,-$ \\
\hline
\end{tabular}

Berdasarkan Tabel 4.3 diatas bahwa didapatkan nilai $\mathrm{BCR}=1,02$ dengan discount rate $11 \%$,- maka angkutan umum dinyatakan layak untuk jadi investasi dan nilai NPV Rp. 10.139.439,- Maka angkutan umum untuk umur ekonomis 10 tahun dinyatakan tidak layak. Dari hasil perhitungan dengan metode IRR didapatkan tingkat suku yaitu 17\%. Kemudian nilai break even point dan pay back period, akan ditampilkan pada Gambar 4.3

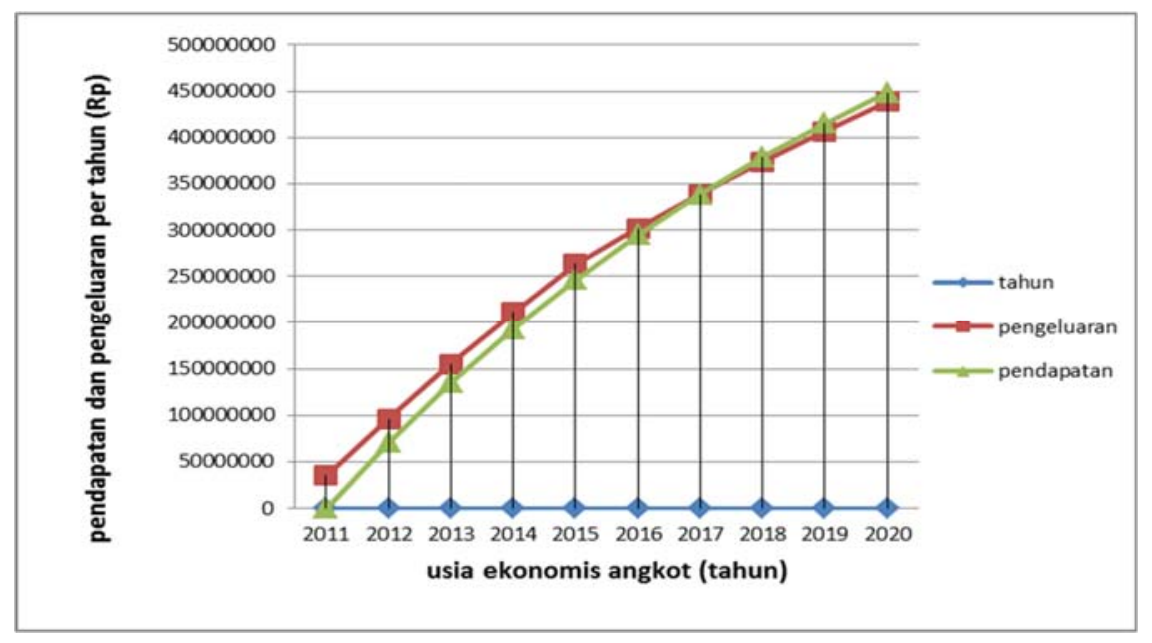

Gambar 4.3. Break even point dan pay back period $(n=10$ tahun dan $i=11 \%)$ 
Berdasarkan Gambar 4.3, bahwa modal sudah kembali dan terdapatnya titik break even pada tahun 2017. Pay back periodnya selama 7 tahun, karena pada tahun ke 2017 modal belum kembali. Nilai sisanya yaitu Rp. 55.000.000,-, usia ekonomis kendaraan selama 10 tahun dengan menjual angkot yang lama diperkirakan belum bisa membeli angkot yang baru dengan cara kredit.

\subsubsection{Angkutan kota untuk umur ekonomis 15 tahun}

Angkutan umum kota diasumsikan keluaran tahun keluaran 2012, dengan sistem pembelian sistim kredit. Direncanakan umur ekonomis selama 15 tahun, nilai pendapatan dan pengeluaran yang digunakan, merupakan pendapatan dan pengeluran rata-rata angkutan umum kota.

Diketahui :

$$
\begin{array}{ll}
\mathrm{P}(\text { pengeluaran awal }) & =\mathrm{Rp} \cdot 120 \cdot 000.000,00 \\
\mathrm{~S}(\text { nilai sisa }) & =\mathrm{Rp} \cdot 35 \cdot 000.000,00 \\
\mathrm{~N}(\text { umur ekonomis }) & =15 \text { Tahun } \\
\text { Depresiasi } & =\frac{\mathrm{P}-\mathrm{S}}{\mathrm{N}} \\
& =\text { Rp. } 13 \cdot 000.000,-\mathrm{Jt} / \text { tahun }
\end{array}
$$

Hasil perhitungan dengan metode BCR, IRR dan NPV, tingkat bunga $11 \%$ bisa dilihat pada Tabel 4.4 di bawah ini. untuk jadi investasi dan nilai NPV Rp. 7.449.457,- maka angkutan umum untuk umur ekonomis 10 tahun dinyatakan layak. Dari hasil perhitungan dengan metode IRR didapatkan tingkat suku yaitu 19\%. Kemudian nilai break even point dan pay back period, akan ditampilkan pada Gambar 4.3.

Tabel 4.4. Hasil perhitungan untuk umur ekonomis 15 tahun

\begin{tabular}{|l|l|l|}
\hline No & Metode & Nilai \\
\hline 1 & BCR & 1,01 \\
\hline 2 & IRR & $19 \%$ \\
\hline 3 & NVP & Rp. 7.449.457,-- \\
\hline
\end{tabular}

Berdasarkan Tabel 4.4 diatas bahwa didapatkan nilai $\mathrm{BCR}=1,01$ dengan discount rate $11 \%$,- maka angkutan umum dinyatakan layak

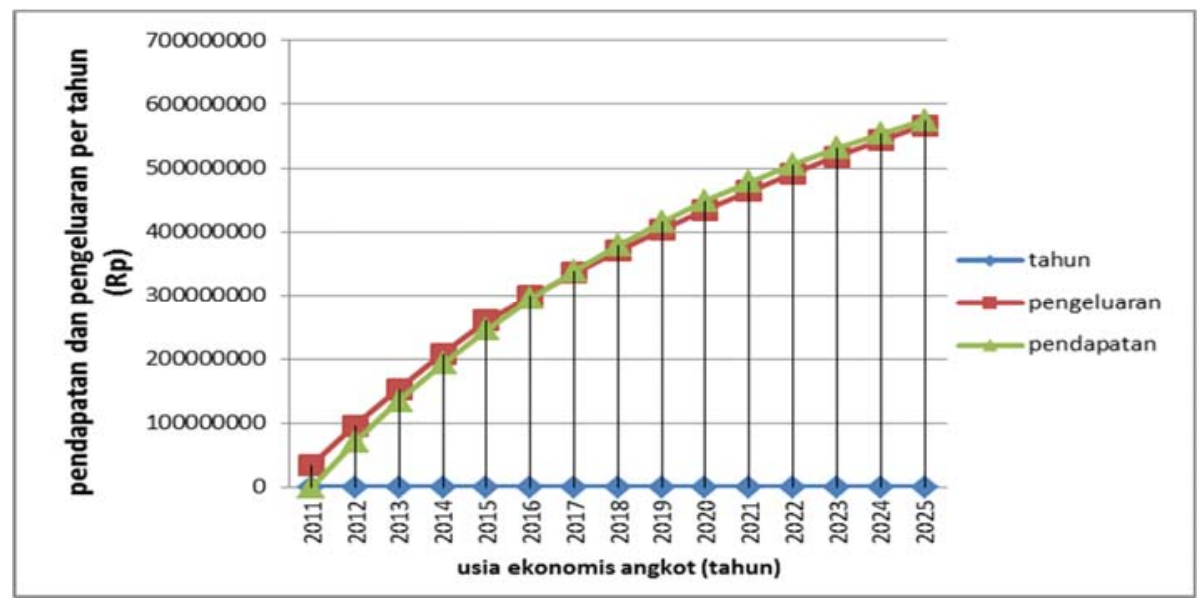

Gambar 4.4. Break even point dan pay back period $(n=15$ tahun dan $i=11 \%)$

Berdasarkan Gambar 4.4, bahwa semakin tinggi tingkat suku bunga sebesar 11\% untuk perencanaan 15 tahun kedepan. Dimana modal sudah kembali dan terdapatnya titik break even setelah tahun 2017 tahun. Pay back periodnya selama 7 tahun, karena pada tahun ke 2006 modal sudah kembali. Nilai 
sisanya yaitu Rp. 35.000.000,-, usia ekonomis kendaraan selama 15 tahun, dimana proyek mendapat untung tetapi tidak bisa dijadikan investasi.

\section{KESIMPULAN}

Berdasarkan hasil penelitian terhadap angkutan umum di kota Pariaman dapat disimpulkan sebagai berikut :

1. Berdasarkan hasil survey angkutan umum Kota Pariaman yang beroperasi memiliki umur ekonomis yaitu 12 tahun, 11 tahun angkutan kota. Dari hasil perhitungan, dengan tingkat bunga $11 \%$ maka yang dinyatakan layak untuk investasi angkot dengan umur ekonomis 12 tahun dan 11 tahun.

2. Berdasarkan hasil perhitungan dari pengeluaran minimum dengan pendapatan minimum angkot, variasi antara pengeluaran maksimum dengan pendapatan maksimum, pengeluaran rata-rata dengan pendapatan rata-rata dengan tingkat suku bunga suku bunga $11 \%$ maka dinyatakan pengeluaran maksimum dengan pendapatan maksimum.

3. Berdasarkan hasil perhitungan pengeluaran minimum dengan pendapatan maksimum angkot, pengeluaran rata-rata dengan pendapatan maksimum, pengeluaran maksimum dengan pendapatan minimum, dengan pendapatan rata-rata dengan tingkat suku bunga $11 \%$ maka dinyatakan pengeluaran rata-rata dengan pendapatan maksimum yang layak investasi.

4. Pada perencanaan investasi angkutan umum kota dengan tingkat bunga $11 \%$ untuk umur ekonomis 5 tahun, dan 10 tahun diperoleh dari hasil perhitungan dengan tingkat bunga 11\%, untuk umur ekonomis 10 tahun dinyatakan layak investasi.

\section{UCAPAN TERIMAKASIH}

Kepada keluaraga tercinta papaku Z.Arsyad Hasan, Ibundaku Yusta Jamar, S.Pdi, Suamiku Azrinal, SH, Putra kesayanganku Aidan Al AriQ Azra, Kakakku Asyrah Arsyad, S.P, dan Adiku AL Malik Arsyad Arsyad, S.Pd.

Kepada, Dosen ku Bapak Purnawan, Ph.D. dan buk Titi Kurniati, MT

\section{DAFTAR KEPUSTAKAAN}

Adler, A, 1984, Evaluasi Ekonomi Proyek-Proyek Pengangkutan, Penerbit Universitas Indonesia, Jakarta.

Ardalan, A, 2000, Economic \& Financial Analysis for Engineering \& Project Management. Technomic Publishing Company, Inc

Argyrous, G, 2004, Cost-Benefit Analysis and Multi-Criteria Analysis. School of social sciences and international studies, UNSW.

Cresswell, 1977. Passenger Transport and The Environment. Prentice Hall, Inc. New Jersey.

Gray, G.E dan L.A. Hoel, 1974, Public Transportation: Planning, Operation and Manajemen. Prentice Hall, Inc. New Jersey.

Joyowijoyono, 1983, Ekonomi Teknik : Jilid 1, Badan Penerbit Pekerjaan Umum, Jakarta.

Morlok, 1988, Pengantar Teknik dan Perencanaan Transportasi (terjemahan Johan K. Hainim), Penerbit Erlangga, Jakarta.

Pearmain, D. K dan Swanson, J, 1990, Stated Preference Techniques : A Guide to Practise - First Edition, London.

Pedoman Teknis Penyelenggara Angkutan Penumpang Umum di Wilayah Perkotaan Dalam Trayek Tetap dan Teratur, Keputusan Direktur Jenderal Perhubungan Darat Nomor : 274/HK.105/DRJD/96

Umar, 2004, Metode Penelitian untuk Skripsi dan Tesis Bisnis, Cetakan ke-6. PT Raja Grafindo Persada. Jakarta.

Vuchic, V. R, 1981, Urban Public Transportation (System of Technology), Prentice Hall, New Jersey. 